distributed in major medical areas. Paediatrics includes a mandatory requirement of this stage presentation Session Paediatric Clinics (SPC) based in the various practice settings in order to instigate the search for knowledge providing a meaningful construction.

Methods A descriptive study, retrospective documentary of SPC presented in 2013 by the undergraduate students of the Faculty of Medicine of Petrópolis, Rio de Janeiro, Brazil.

Results There were 70 SCP, $70 \%$ from the paediatric ward, $12.86 \%$ of the NICU and $17.14 \%$ of the other scenarios. Active participation in the choice of topic, review and submission process was on average 3 students and the number of listeners was 40/SCP. The chosen themes, 52,86\% are not part of the curriculum previously offered. Infectious diseases have contributed to $37,14 \%$ of realisation of the SPC.

Conclusion This study shows for the promotion of proactive methodologies as supporters of the integration of the student as the protagonist of the teaching- learning process and therefore should be encouraged. As for the themes chosen believe that awakening to the search for new knowledge has been significantly.

\section{PO-0968 MAIN DEATH ETIOLOGIES OF CATALAN CHILDREN. EXPERIENCE OF THE ADMITTED PATIENTS IN A TERTIARY HOSPITAL}

${ }^{1} \mathrm{~S}$ Navarro, ${ }^{1} \mathrm{MR}$ Escobar, ${ }^{1 S} \mathrm{~S}$ Ciprés, ${ }^{1} \mathrm{M}$ Palomares, ${ }^{2} \mathrm{G}$ Gelabert, ${ }^{3} \mathrm{JJ}$ García. ${ }^{1}$ Pediatric Palliative Care Unit, Hospital Sant Joan de Déu, Barcelona, Spain; ${ }^{2}$ Clínical Archives and Documentation, Hospital Sant Joan de Déu, Barcelona, Spain; ${ }^{3}$ Pediatrics, Hospital Sant Joan de Déu, Barcelona, Spain

\subsection{6/archdischild-2014-307384.1587}

Background and aims Paediatric palliative care is an essential aspect of medical practice for patients who need end-of-life attendance. The better understanding of the main death causes allows to anticipate the future complications in the final stage. The aim is to describe the epidemiology and characteristics of deaths at childhood in Catalonia and specifically in a tertiary paediatric hospital.

Methods Review data from the National Statistics Institute (http://pestadistico.inteligenciadegestion.msssi.es) on mortality of people aged 0-19 years old, during the period from 2007 to 2011. Analyse the main general causes of death by ICD (International Code of Disease) collected in death certificate and compare them with our experience.

Results During the period from 2007 to 2011, a total of 2.282 deaths were registered in Catalonia (59\% males, $41 \%$ females). The mortality rate varies by age (Graph 1). In Catalonia the most frequent causes of death were conditions originated in the perinatal period (COPP) (27\%), external causes (18\%),

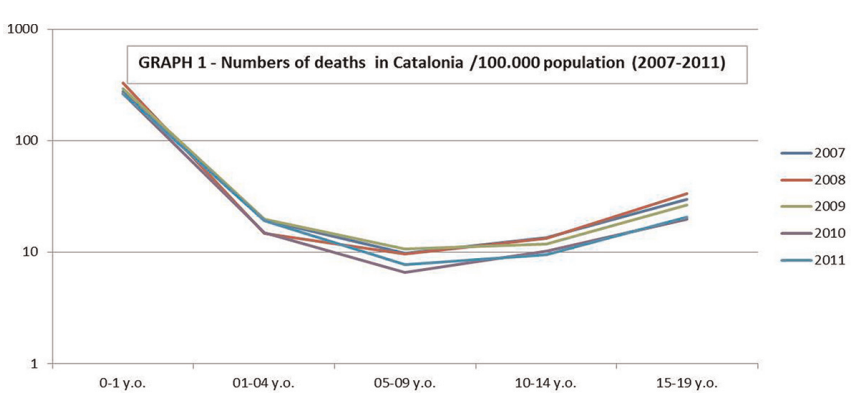

Abstract P0-0968 Graph 1 Numbers of deaths in catalonia/100.000 population (2007-2011)

congenital malformations (15\%) and neoplasms (11\%)(Table 1). The epidemiological study in our centre shows that 487 patients died in this period. The mean age was 3.5 years. According to sex, $47 \%$ were female and $53 \%$ male. The average length of hospitalisation was 12 days (range: 1-167 days). In our hospital, the most frequent causes of death in inpatients were COPP (45\%), diseases of the respiratory system (17\%) and neoplasms (15\%)(Graph 2).

Conclusions In accordance with the literature, during the first year there is a peak in the mortality rate. In this period the main causes of death are COPP and congenital malformations. In adolescence the main causes of death are external causes and malignancy. In our hospital, almost a half of the total deaths occur in the first month of life due to COPP. Every centre should know his epidemiology of the main causes of death.

\section{PO-0969 WITHDRAWN}

\section{PO-0970 A NEW GROWING PAINS DIAGNOSTIC TOOL: EVALUATION IN A MEDITERRANEAN CLINICAL SAMPLE}

${ }^{1} \mathrm{M}$ Vassilopoulou, ${ }^{2} \mathrm{~A}$ Spathis, ${ }^{2}$ Paspati, ${ }^{3} \mathrm{M}$ Tsolia. ${ }^{1} \mathrm{PICU}$, Penteli's Children Hospital, Athens, Greece; ${ }^{2}$ Orthopedic Clinic, Penteli's Children Hospital, Athens, Greece; ${ }^{3} 2 n d$ University Pediatric Clinic, University of Athens Medical School, Athens, Greece

\subsection{6/archdischild-2014-307384.1588}

Background "Growing pains (GP)" is the most common musculoskeletal complaint in childhood.

Aim To investigate the sensitivity and specificity of a previously validated questionnaire, for the diagnosis of GP.

Methods From 01/2013-12/ 2013, a questionnaire (Tb. 1), was administered to parents of children aged 3-8 years, who visited an orthopaedic clinic of a general children's hospital, as outpatients, complaining of lower limb pain of no apparent traumatic

\begin{tabular}{|c|c|c|c|c|c|c|c|c|}
\hline & & & $0-1$ у.о. & $2-4$ у.о. & 5-9 у.о. & $10-14$ у.о. & $15-19$ у.о. & TOTAL \\
\hline II & C00-D48 & Neoplasms & 15 & 50 & 59 & 53 & 68 & 245 \\
\hline IV & E00-E90 & Endocrine, nutritional and metabolic diseases & 40 & 24 & 6 & 7 & 12 & 89 \\
\hline VI & G00-G99 & Diseases of the nervous system & 59 & 32 & 10 & 23 & 35 & 159 \\
\hline$x$ & J00-J99 & Diseases of the respiratory system & 20 & 20 & 10 & 9 & 15 & 74 \\
\hline $\mathrm{XVI}$ & P00-P96 & Certain conditions originating in the perinatal period & 624 & 1 & 0 & 1 & 0 & 626 \\
\hline XVII & Q00-Q99 & Congenital malformations, deformations and chromosomal abnormalities & 284 & 28 & 8 & 11 & 8 & 339 \\
\hline XVIII & R00-R99 & Symptoms, signs and abnormal clinical and laboratory findings, not elsewhere classified & 93 & 26 & 6 & 12 & 18 & 155 \\
\hline \multirow[t]{2}{*}{$X X$} & V01-Y98 & External causes of morbidity and mortality & 23 & 59 & 43 & 46 & 237 & 408 \\
\hline & & Others: Infectious, diseases of the blood, digestive and circulatory system... & 46 & 46 & 22 & 31 & 42 & 187 \\
\hline
\end{tabular}

